\title{
APPLICATION OF NFC TECHNOLOGY IN RAILWAY PASSENGER TRANSPORT BY INTRODUCING NEW PRODUCTS
}

Near Field Communication (NFC) is a new trend in the world of information technology, which has a profound impact on all spheres of life. This technology is currently being applied in public transport services, which is confirmed by a number of passenger handling methods that use NFC throughout Europe. NFC technology offers convenience and mobility to users of public passenger transport. With NFC carriers may expand their portfolio of NFC supported services. This paper presents possible application of the NFC technology in railway passenger transport by introducing new products, and the possibility to expand the business portfolio of railway operators.

Keywords: NFC technology, railway passenger transport.

\section{Introduction}

This article is focused on the design of implementation of NFC technology in railway passenger transport in Slovakia in the form of new products called "National Railway Card" and "Travel Easy". The implementation of NFC in railway passenger transport will bring benefits to the state, carriers as well as passengers. These benefits will include:

- faster passenger handling,

- less time waiting in line for travel documents,

- increased number of potential passengers,

- expanded service portfolio of carriers,

- better data summarization,

- contribution in the field of environmental policy of carriers [1 and 2].

\section{2. "National Railway Card"}

The basis of the "National Railway Card" is a contactless chip card (CCHC). Therefore, every passenger would have to possess a CCHC. The passenger could choose one of two $\mathrm{CCHCs}$ - a basic card or a personal card.

The basic card would be designed for "casual" passengers who do not use railway passenger transport on a regular basis. $\mathrm{CCHC}$ would cost $2 €$ and would be valid for five years. The card would use the basic fare of carriers without any discount and would be transferrable to another user/passenger [3].

The personal CCHC would be designed for pupils/ students and working people, who use the railway passenger transport to get to work, for pensioners, disabled people and other groups of people. CCHC would be issued upon filling in personal data and attaching a photo of the person concerned. Passengers entitled to a discount would have to submit a form proving their entitlement to a discount.

\section{Usage}

CCHC could be used in the system "National Railway Card" with all carriers operating railway passenger transport in Slovakia. CCHC could be used in two ways - on the basis of a pre-purchased travel document or by the method "Pay as You Travel."

Both methods would operate based on a subscription model, i.e. the passenger would have to store the travel document (TD) or deposit cash on his/her CCHC. The passenger could travel with a pre-purchased travel document stored on his/her $\mathrm{CCHC}$ with all carriers. The passenger could purchase the travel document in a cash desk, a stationary vending machine or over the Internet. The passenger would have to check-in at the beginning and check-out at the end of his/her journey. Based on these actions, the clearing operator

\footnotetext{
* ${ }^{1}$ Eva Brumercikova, ${ }^{1}$ Bibiana Bukova, ${ }^{1}$ Pavol Kondek, ${ }^{2}$ Pawel Drozdziel

${ }^{1}$ Department of Railway Transport, Faculty of Operation and Economics of Transport and Communications, University of Zilina, Slovakia

${ }^{2}$ Politechnika Lubelska, Lublin, Poland

E-mail: bibiana.bukova@fpedas.uniza.sk
} 
would be able to redistribute the income among different carriers [4]. In case of commercial train carriers, such as RegioJet, Arriva and LEO Express, the clearing operator would automatically assign payments to the carriers based on the pre-purchased travel document that would be issued with a reservation of a specific seat in a particular train. Figure 1 shows a flowchart of the method of transport based on a prepurchased travel document.

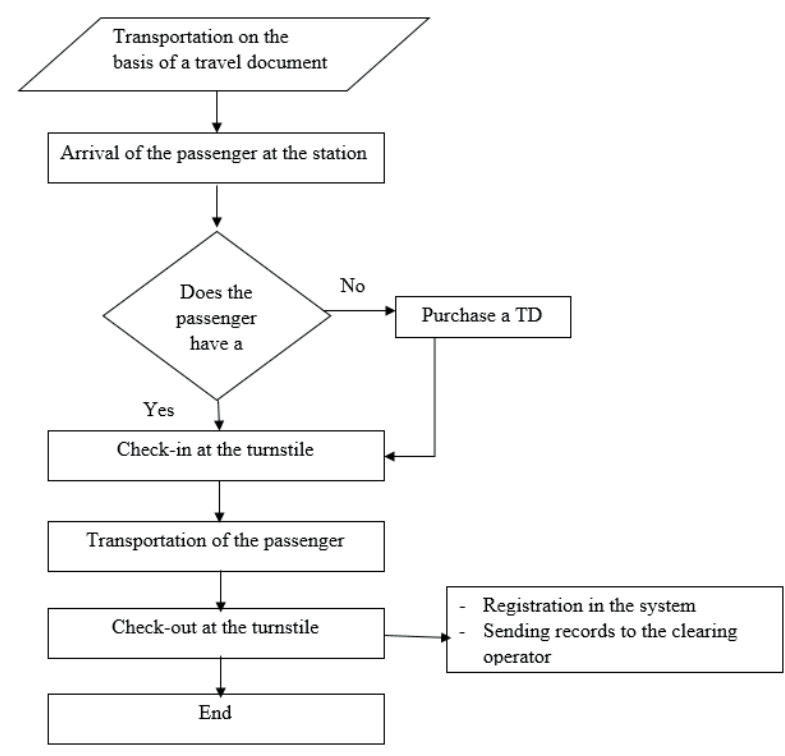

Fig. 1 Flowchart - TD

Figure 2 shows a flowchart of the method of transport "Pay as You Travel". This transportation system could be used in trains of Zeleznicna spolocnost Slovensko and RegioJet on the track Komarno - Bratislava. The system would operate in a way that the passenger would deposit enough cash on his/ her $\mathrm{CCHC}$ and the price of transport would be automatically calculated at the end of the journey based on check-in/checkout and would be then subtracted from his/her $\mathrm{CCHC}$, all just in a few seconds.

The fare would be determined based on the type of $\mathrm{CCHC}$, either as a basic fare based on a basic card or as a reduced fare based on a personal card. It would be possible for the carriers to offer various loyalty programs for a personal $\mathrm{CCHC}$, since this technology makes it possible [5].

Responsible for income redistribution would be a newly created entity - the clearing operator. Figure 3 shows the scheme of redistribution of income from travel documents. First, the passenger would purchase a travel document that would be stored on his/her CCHC or he/she would deposit some cash on his/her CCHC.

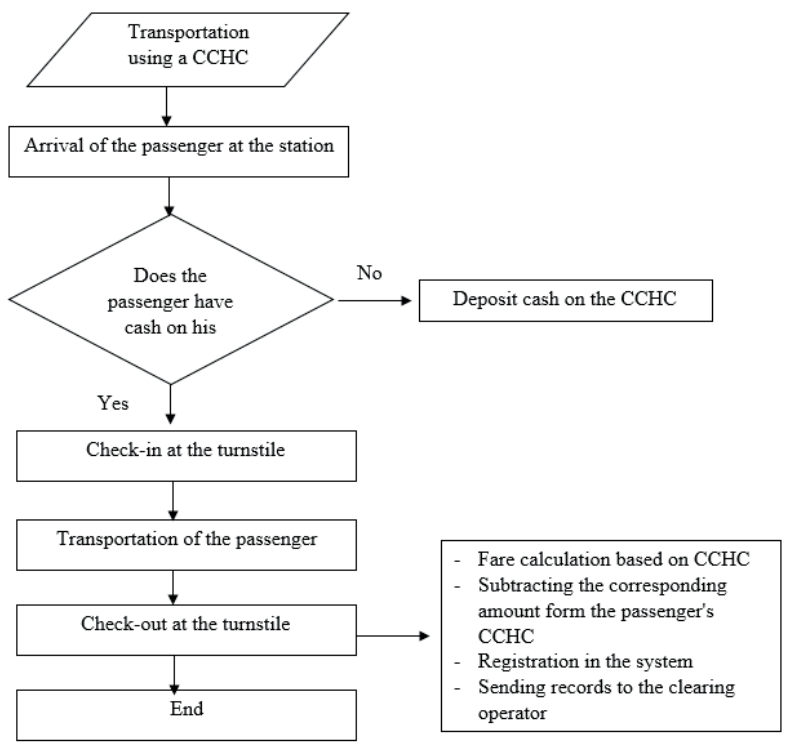

Fig. 2 Flowchart "Pay as You Travel"

The fare would be sent either to the bank, in case the passenger has purchased the travel document by credit card, or to sellers of travel documents (cash desk, stationary vending machine). At the end of the whole process all the funds would be sent to the clearing operator. Part of the funds from the income would go back to the sellers of travel documents or to the bank to cover their costs. The main part of the income would be redistributed by the clearing operator to the carriers. The income would be redistributed in a contractually agreed way based on the share of services of different carries used.

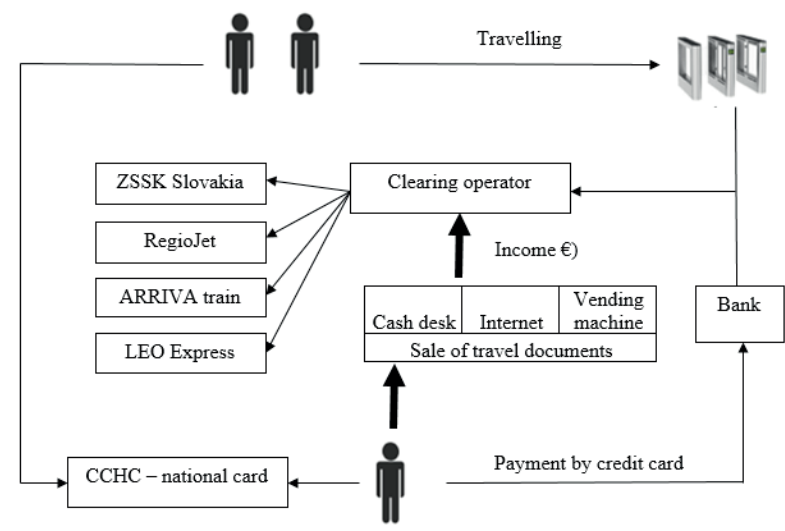

Fig. 3 Income redistribution scheme

Passengers travelling by rail would be recorded on the basis of check-in/check-out from the system. Based on these records, the clearing operator would be able to calculate the respective share of each carrier [6].

CCHCs would also replace various carriers' loyalty cards and passports, based on which the passenger is entitled to 
a discount. All relevant information would be filled in by the passenger during $\mathrm{CCHC}$ registration and would be stored on the card, based on which the system would always determine the correct tariff for the individual passenger.

\section{Mobile phone application - product "TRAVEL EASY"}

NFC technology can be used in the form of a mobile phone application. The product "Travel Easy" is targeted at travellers who actively use their mobile phone and would prefer to purchase travel documents with a mobile app. The product "Travel Easy" could be designed as an additional service to the existing passenger handling service. In this case, the carrier would have to install NFC tags - contact points at railway stations or in the transport vehicles. An NFC tag, i.e. the contact point would be composed of an NFC chip and a QR code for wider public use. At each of these points there would be a simple manual in case of doubt with the use of the system by passengers.

Passenger using this technology would have to meet the following conditions:

- own a mobile phone,

- own an NFC SIM card,

- have a registered account on the Internet,

- download the "cestuj jednoducho" application,

- Internet access.

Passenger would be provided with NFC SIM cards by their mobile operator (Telefónica O2, Orange, Slovak Telekom). Since there already is cooperation between mobile operators and railway carries, cooperation would be ensured.

Usage

In order for a passenger to start using the system, he/ she would have to register through the website. During the registration he/she would fill in all personal data and his/ her phone number. If he/she was the owner of a loyalty card (e.g. KLASIK RAILPLUS) or a card based on which he/ she would be entitled to a discount (e.g. ISIC), he/she would assign it to his/her account. Then he/she would procure an NFC SIM card from his/her mobile operator and download the application.

There would be the option to check-in/check-out through a QR code in the application. This would be for the case that there would be any problem with NFC, as well as for a broader range of travellers who could use this application even if they did not own a mobile phone with NFC.

Control during the journey could be done in two ways:

- upon check-in a TD would be sent to the passenger's NFC on his/her SIM card and during control the passenger would open the application and put his mobile phone to the scanning device - the mobile phone would function as a $\mathrm{CCHC}$ with a stored TD, or

- upon check-in the passenger's TD would be sent to the application in form of a QR code, which he/she would show in case of control.

The flowchart in Fig. 4 shows the whole process of transport and the way of paying for the TD, which could be done in two ways.

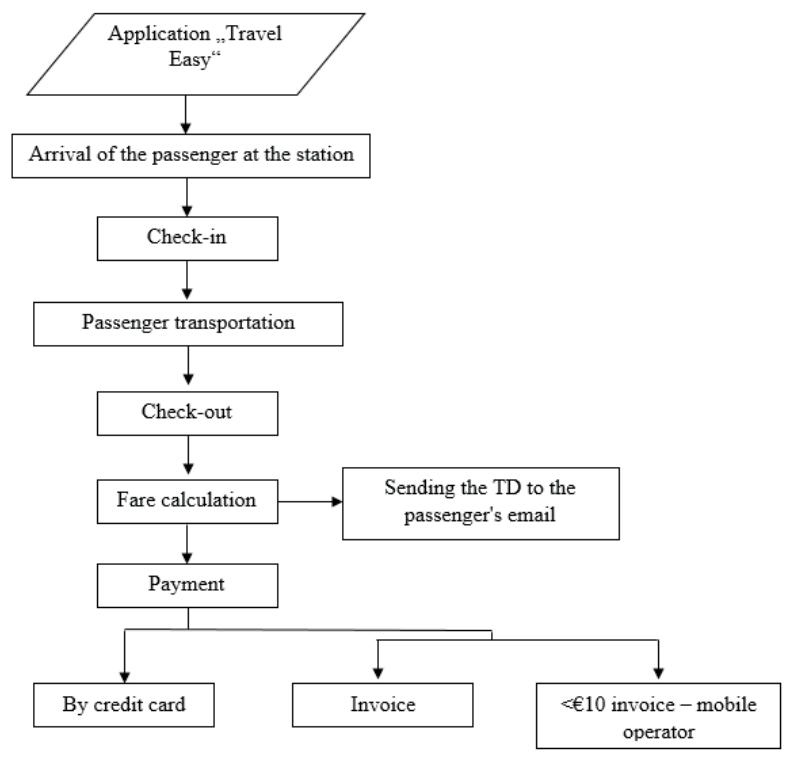

Fig. 4 Flowchart of the application "TRAVEL EASY"

The travel document could be paid in two ways:

- by credit card immediately after the journey - the credit card would be connected with the passenger's account and after system data synchronization the amount would be automatically subtracted from the traveller's account,

- by invoice: every month the passenger would receive an invoice with the sum of all TDs in that month. If the amount was less than $€ 10$, it would be automatically added to the invoice issued by the mobile operator; if the amount was higher, a separate invoice would be mailed to the passenger' address provided during registration.

\section{Conclusion}

The NFC technology is an essential component of both products proposed. However, the products differ in the equipment used. The first product uses a $\mathrm{CCHC}$ card, the second uses a mobile phone. The main difference between these products is that the first product is of a bigger size and the impact on the society would be very large, since almost each passenger would have to get a CCHC. The second 
product, i.e. the system "Travel Easy" is designed as an additional form of selling travel documents.

The purpose of both of these products is to simplify and speed up the handling of passengers. These products have a great perspective for the future through the increasingly expanding market with NFC technology. The product "National Railway Card" could be later extended by adding other kinds of public passenger transport to the national integrated system of public passenger transport in the Slovak Republic.

\section{Acknowledgment}

The paper is supported by the VEGA Agency by the Project $1 / 0095 / 16$ "Assessment of the quality of connections on the transport network as a tool to enhance the competitiveness of public passenger transport system", that is solved at Faculty of Operations and Economics of Transport and Communication, University of Zilina.

\section{References}

[1] KOMSTA, H., BRUMERCIKOVA, E., BUKOVA, B.: Application of NFC Technology in Passenger Rail Transport. Transport Problems - Scientific J., No. 3, 2016, 43-53. ISSN 1896-0596.

[2] KAMPF, R., LIZBETIN, J., LIZBETINOVA, L.: Requirements of Transport System User. Communications - Scientific Letters of the University of Zilina. No. 4. 2012, 106-108. ISSN 1335-4205.

[3] BRUMERCIKOVA, E., BUKOVA, B., KRZYWONOS, L.: NFC Technology in Public Transport. Communications - Scientific Letters of the University of Zilina, No. 2, 2016, 20-25. ISSN 1335-4205.

[4] BRUMERCIK, F., LUKAC, M., CABAN, J.: Unconventional Powertrain Simulation. Communications - Scientific Letters of the University of Zilina, No. 2, 2016, 30-33. ISSN 1335-4205.

[5] BRUMERCIK, F., DANKO, R.: Transport Application of Hybrid Simulation. Communications - Scientific Letters of the University of Zilina, No. 2, 2014, 20-24. ISSN 1335-4205.

[6] HANZL, J., BARTUSKA, L., ROZHANSKAYA, E., PRUSA, P.: Application of Floyd's Algorithm on Transport Network of South Bohemian Region. Communications - Scientific Letters of the University of Zilina, No. 2, 2016, 68-71. ISSN 1335-4205. 